\title{
PRODUCTION OF TOMATO CAROTENOIDS (SOLANUM LYCOPERSICON MILL.) DURING DIFFERENT FORCING PERIODS
}

\author{
Edit KRISTó, FERENC LANTOS \\ University of Szeged Faculty of Agriculture, Hódmezővásárhely, Hungary \\ kredit96@gmail.com
}

\begin{abstract}
Tomatos are one of the most widely grown and consumed vegetables in the world. It does not only meet the needs of the fresh market, but also has become an essential ingredient for the food industry. Since 2012, however, intensive soilless forcing is gaining ground on increasingly large areas, using more and more modern technologies. This will make the fulfilling of our domestic tomato demands more continuous, however we can also produce for exports.

However, the yield is not all! Continuous forcing also means that the plant grows during the winter-spring period when biological and other physical factors are not in line with nature. During this period, the necessary factors must be artificially provided for the plant! There may be a question as to what kind of quality differences can be found between autumn-winter and spring-summer tomatoes?! The most valuable carotene of the tomato is the red lycopene, which is continuously produced during ripening. However, elevated air temperatures above $32{ }^{\circ} \mathrm{C}$ can stop the production of lycopene and then the yellow $\beta$-carotene becomes a stronger colour in the berry. During my work, I studied the ratio of the production of the two carotenoids in different types in different forcing periods.
\end{abstract}

Keywords: tomato, lycopene, $\beta$-carotene, all carotene substances

\section{INTRODUCTION}

Tomato belongs to the family of Solanaceae and to the genus Lycopersicon. Lycopersicon is made up of two main subgenera. The basis of the classification was initially the colour of tomato. The green crops are Eriopersicon, and the coloured (red, yellow) crops are in Eulycopersicon (MÜLLER, 1940). RICK (1976) grouped the species into how easy or difficult it is to cross the cultivated tomato species. Its fruit is called berries. Its shape is varied: from the flat round to the plum- and the pear-shaped, all the intermediate shapes can occur. The colour of the berry is given by the shell and the flesh. The tomato with colorless skin and yellow flesh is yellow, the one with colorless skin and red flesh is red, while the one with yellow skin and red flesh is red (LOCAL, 1999). The red colour of the fruit is due to the lycopene produced continuously. Lycopene $\left(\mathrm{C}_{40} \mathrm{H}_{56}\right)$ is an open-chain compound, strong antioxidant. It can also be made from petrol-ether in the form of red needle crystals. It can be typically found in the berry of tomatoes, and in the flowers, roots, seeds and fruits of higher-order plants (SZEKERES ET AL., 1967; GASZTONYI ET AL., 1992). During the processing of the tomato and during its ripening, above $26{ }^{\circ} \mathrm{C}$ berry temperature, the production of lycopene stops and it becomes $\beta$-carotene (ISHIDA, 1990). Beta-carotene is also a bicyclic, yellowish compound. It has the same formula as $\alpha$ carotene. It is converted into vitamin A in the body. The transformation occurs in the liver by the action of the carotinase enzyme (SzEKERES ET AL, 1967). The $\beta$-carotene is the most prominent member of the group of carotenoids, natural colorants that occur in the human $\operatorname{diet}$ (BRITTON ET AL., 2008). As a tetraterpenoid it consists of 40 carbon atoms in a core structure of conjugated double bonds substituted with $2 \beta$-ionone rings. Due to its extended system of 9 fully conjugated double bonds, $\beta$-carotene shows a major absorption peak in the visible spectrum with a maximum at $\sim 450 \mathrm{~nm}$, responsible for the orange to red color of the compound (BRITTON ET AL., 1995). Lycopene is a lipophilic, unsaturated carotenoid, 
found in red-colored fruits and vegetables, including tomatoes, watermelon, papaya, red grapefruits, and guava. The main activity profile of lycopene includes antiatherosclerotic, antioxidant, anti-inflammatory, antihypertensive, antiplatelet, anti-apoptotic, and protective endothelial effects, the ability to improve the metabolic profile, and reduce arterial stiffness (MozOS ET AL., 2018). The color of lycopene is directly related to its isomeric form. The all-trans isomer and most other isomers of lycopene are red, whereas tetra-cis-lycopene possesses an orange hue (ZECHMEISTER, 1944).

Both carotenoids are very important for humna body, but the market favours lycopene-rich red tomatoes. Due to the yellow colour of the berry, a potassium deficiency is often suspected during propagation, but the cause of this phenomenon is actually the elevated temperature.

To address this topic, we have set the following aims:

- Detection of the two most important carotenes of tomato production, lycopene and $\beta$-carotene, with HPLC methods.

- Analysis of changes in carotenoid varieties of harvested types in the context of the forcing periods and the total carotene production.

\section{MATERIAL AND METHOD}

Harvesting of tomato berries was carried out at the greenhouse plant of Floratom Kft. in Szeged. In the greenhouses, the intensive cultivation of different types of tomatoes is carried out on coir, applying thermal water heating. We collected 3-3 berries from three different types of varieties during the picking period. In March 2017 we studied the tomatoes collected from the winter and spring period, and the berries collected from the summer-and-autumn period were studied in November 2017. Our laboratory tests were carried out by HPLC instrumental examination in the special carotene laboratory of the Pharmacognosy Institute of the University of Pécs.

The examined tomato genotypes:

- Quentero $F_{1}$ : medium-mature, with a berry-weight of 130-150 g, round-shaped, with a vivid red skin

- Direktion $F_{1}$ : intense, plum-shaped, vibrant red-coated, continuous growth

- Ardiles $\mathrm{F}_{1}$ : intensive ripening, soft berry 35-40 g, mini plum shaped, deep red colored

The most important work phases of the laboratory detection methodology:

- drying of the examined tomato berries at $60^{\circ} \mathrm{C}$, separately for each genotype,

- measurement and egalitization,

- storage in dry place,

- solving in acetone (24 hours),

- filtration, sedimentation,

- soaking in dimethyl ether,

- separation of fractions with dimethyl ester,

- vacuum distillation,

- another dissolution in ether,

- KOH saponification,

- instrument definition of carotenes HPCL. 


\section{RESULTS}

On the basis of the instrumental tests, the lycopene and $\beta$-carotene concentrations of the berries of the harvested tomatoes were determined. The HPLC chromatographic diagrams show the presence of several carotenoids, of which only the results of the two mentioned carotenoids (lycopene and $\beta$-carotene) have been considered (Figures 1,2 and 3). Table 1 and Table 2 show the average values of berry lycopene, $\beta$-carotene and total carotene content measured in 3 replicates.

Regardless of seasons, the lycopene was present in very high concentrations in all cultivated tomatoes, although at different concentrations per variety. The least amount of lycopene was in the winter-spring forced Direktor $F_{1}$ tomato. The highest amount of it was in the winter-spring forced Ardiles $F_{1}$ berries. In tomato berries from summer-autumn, there was a high variation between $\beta$-carotene percentages. Ardiles showed a deviation of $4.75 \%$, Direktion $8.98 \%$ deviation, and the largest difference was in the Quentero $\mathrm{F}_{1}$ tomato with $19.91 \%$.

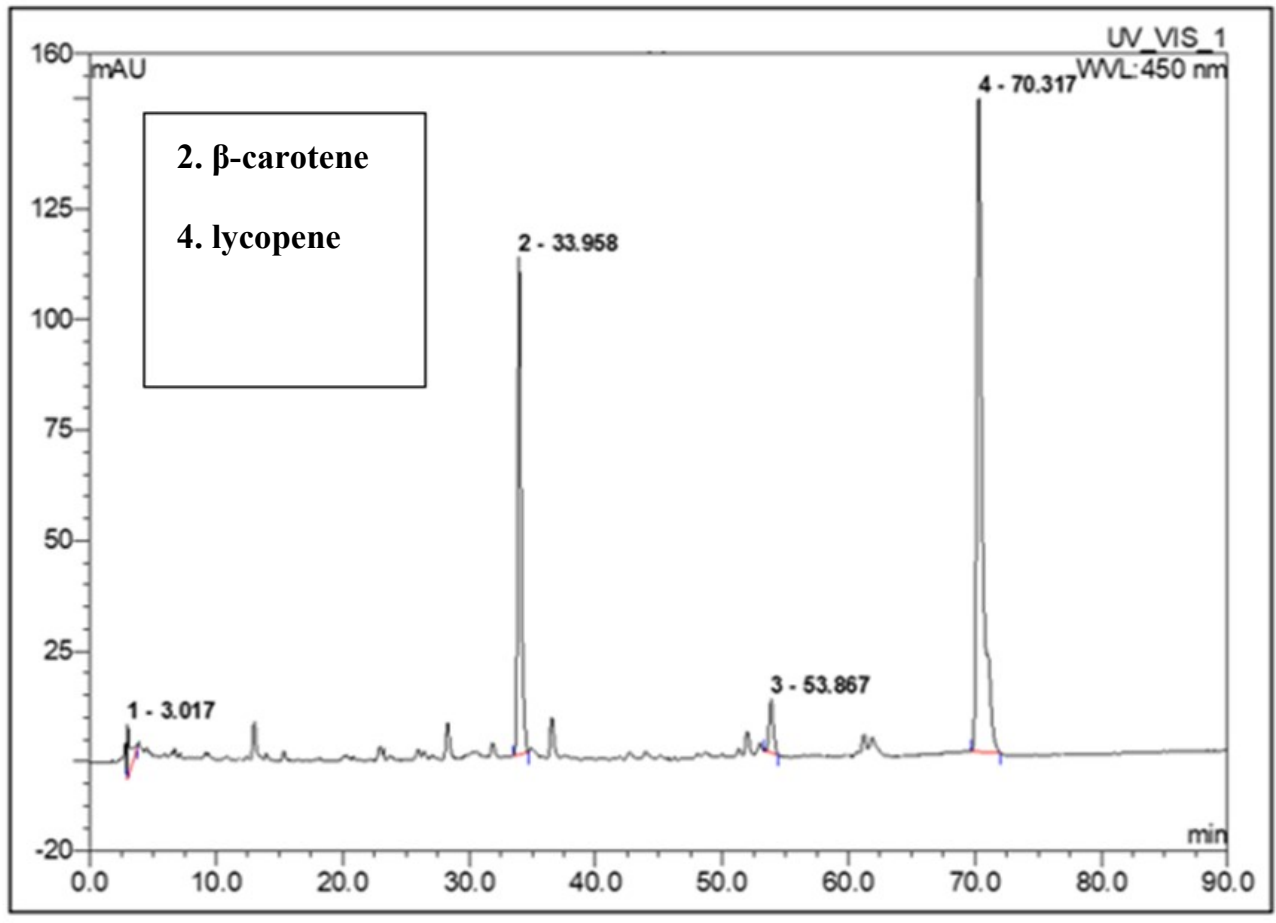

Figure 1. The instrumental test result of Direktion F1 tomato berries 


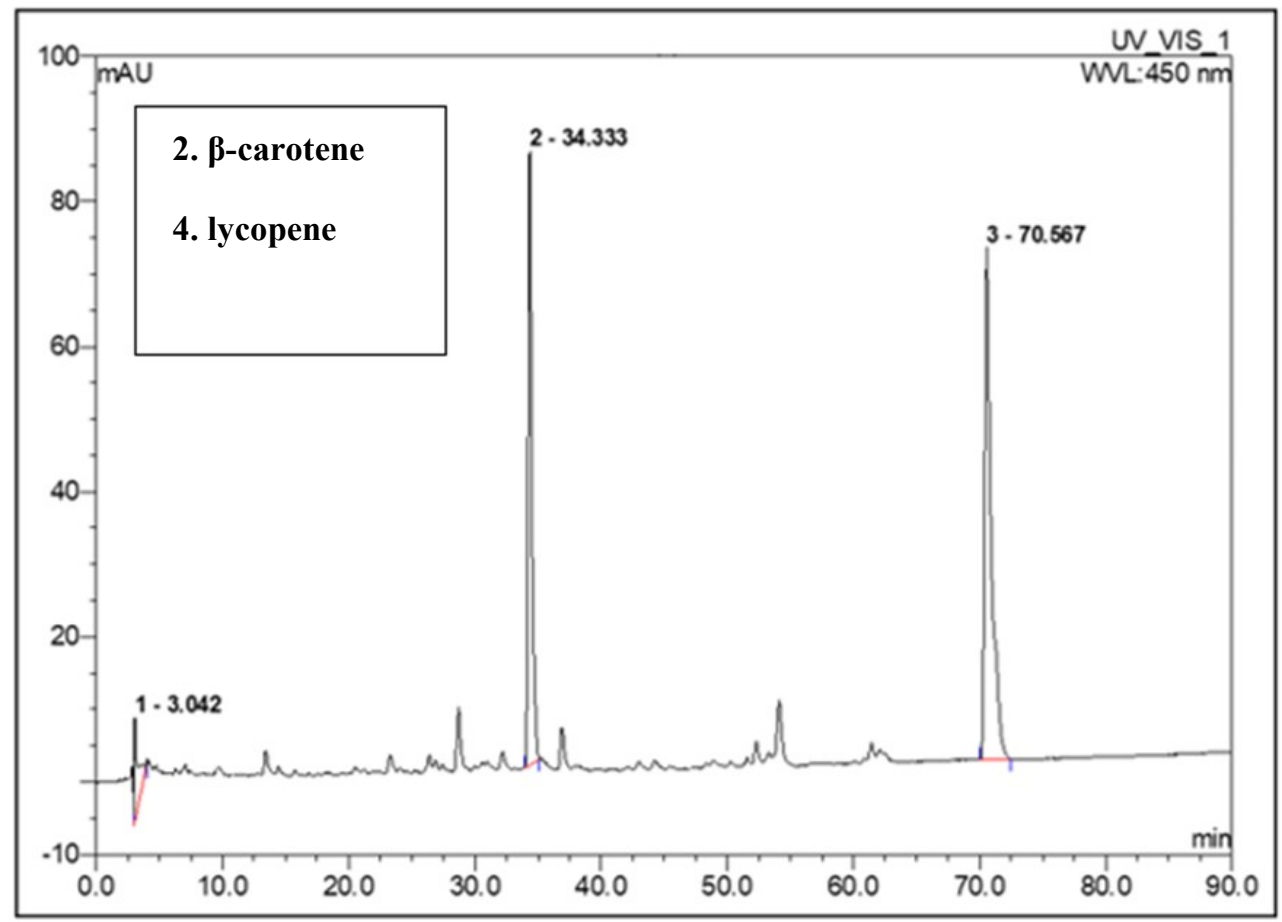

Figure 2. The instrumental test result of Quentero F1 tomato berries

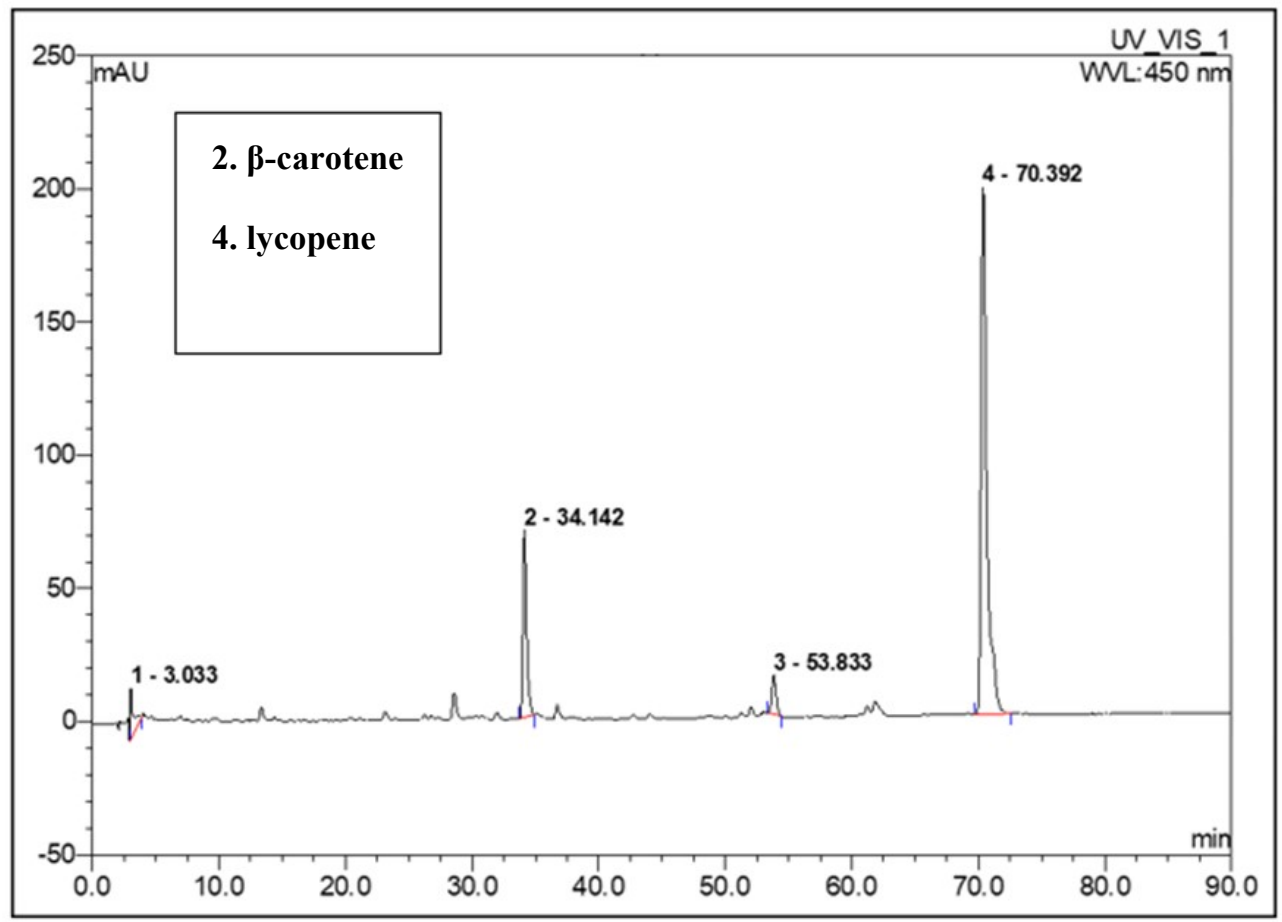

Figure 3. The test result of Ardiles tomato berries 


\section{CONCLUSIONS}

A number of studies have suggested that certain factors influence the efficiency of $\beta$ carotene absorption and/or conversion to retinol. Several scientific reports have indicated a negative relationship between $\beta$-carotene status and type 2 diabetes. Although the FDA concluded that there is "no credible evidence to support an association between lycopene intake and a reduced risk of prostate, lung, colorectal, gastric, breast, ovarian, endometrial or pancreatic cancer," based on the results of our work, we can recommend tomatoes from winter-spring forcing for more intensive utilization because human body can get more lycopene and more antioxidants of carotene origin.

\section{ACKNOWLEDGEMENTS}

We would like to thank the Floratom horticulturists in Szeged who allowed us to gather tomatoes. We thank Professor József Deli for his work, his time for us, and the opportunity to carry out our studies. Thanks to Roland Lukács, who followed our work with all his patience and helped us in the practical implementation.

\section{REFERENCES}

BRITton, G. (1995): UV/visible spectroscopy. In: Britton, G., Liaaen-Jensen, S., Pfander, H. (Eds.): Carotenoids, Vol. 1B Spectroscopy. Birkhäuser Verlag, Basel, Switzerland. Pp. 13-62.

Britton, G., LiaAen-Jensen, S., Pfander, H. (2008): Carotenoids. Birkhäuser Verlag, Basel, Switzerland. 647 P.

GaszTOnyi, K., LÁsztity, R. (1992): Food chemistry 1. Mezőgazda Kiadó, Bp. Pp. 240243.

ISHIDA (1990): Extraction, isolation and purification of $\beta$-carotene. $23 \mathrm{p}$.

Mozos, I., Stoian, D., Caraba, A., Malainer, C., Horbanczuk, J., Atanasov, G. (2018): Lycopene and vascular health. Front Pharmacol 9: 521.

MÜLLER, C.H. (1940): A revision of the genus Lycopersicum. USDA Miscellaneous Publication, No 383 USDA, Washington, D.C. Pp. 407-412.

RicK, C.M. (1976): Tomato (family Solanaceae). In: Simmonds, N.W. (ed): Evolution of crop plants. New York: Longman Publications in Brandt S.: Ph.D. Dissertation. Gödöllö, 2007. Pp. 268-273.

SzEKERES, L. (1967): Organic chemistry. Mezőgazdasági Kiadó, Bp. Pp. 2016-2018.

ZECHMEISTER, L. (1944): Cis-trans isomerization and stereochemistry of carotenoids and diphenyl-polyenes. Chem Rev. 34(2): 267-344. 